\title{
Revalidação de Acocoelidia DeLong (Hemiptera, Cicadellidae, Neocoelidiinae) ${ }^{1}$
}

\author{
Ana Paula Marques-Costa ${ }^{2,3} \&$ Rodney R. Cavichioli ${ }^{2}$
}

${ }^{1}$ Contribuição número 1774 do Departamento de Zoologia, Universidade Federal do Paraná.

${ }^{2}$ Departamento de Zoologia, Universidade Federal do Paraná, Caixa Postal 19020, 81531-980 Curitiba-PR, Brasil. cavich@ufpr.br ${ }^{3}$ Endereço atual: Departamento de Biologia, Universidade Federal de Sergipe, Av. Marechal Rondon, s/n, Jardim Rosa Elze, $49100-000$ São Cristóvão-SE, Brasil. apmc@ufs.br

\begin{abstract}
Revalidation of Acocoelidia DeLong (Hemiptera, Cicadellidae, Neocoelidiinae). Acocoelidia DeLong, 1953 is removed from the synonymy of Coelidiana Oman, 1936. The genus and the species Acocoelidia anomala DeLong, 1953 and Acocoelidia unipuncta DeLong, 1953 are redescribed. Illustrations and geographical distribution of the species are provided.
\end{abstract}

KEYWORDS. Geographical distribution; Neocoelidiinae; redescription; taxonomy.

RESUMO. Revalidação de Acocoelidia DeLong (Hemiptera, Cicadellidae, Neocoelidiinae). Acocoelidia DeLong, 1953 é removido da sinonímia com Coelidiana Oman, 1936. O gênero e as espécies Acocoelidia anomala DeLong, 1953 e Acocoelidia unipuncta DeLong, 1953 são redescritos. Ilustrações e a distribuição geográfica das espécies são fornecidas.

PALAVRAS-CHAVE. Distribuição geográfica; Neocoelidiinae; redescrição; taxonomia.

DeLong (1953) descreveu Acocoelidia relacionando-o com Coelidiana Oman, 1936, e tendo como espécie-tipo Acocoelidia unipuncta, descrita a partir de holótipo macho, localidade-tipo Iguala, Guerrero, México. Incluiu também no gênero Acocoelidia anomala, descrita a partir de um espécime macho da Costa Rica. Forneceu chave de identificação para separação dos gêneros e subgêneros de Neocoelidiinae conhecidos até então, incluindo Acocoelidia.

Kramer (1964) ao revisar os gêneros de Neocoelidiinae, sinonimizou Acocoelidia DeLong, 1953 sob Coelidiana, transferindo então as espécies $A$. unipuncta e $A$. anomala para Coelidiana. Ilustrou as genitálias dos machos de Coelidiana rubrolineata (Baker, 1898) (espécie-tipo de Coelidiana) e Coelidiana unipuncta (DeLong, 1953) e definiu a distribuição geográfica de Coelidiana, como sendo do Sul do México até o Brasil.

Com base no estudo das espécies válidas de Coelidiana e das espécies de Acocoelidia sinomizadas por Kramer (1964), observou-se que estas últimas diferem de Coelidiana principalmente pelos caracteres das asas anteriores (posição das células apicais) e pela margem anterior da coroa, em vista dorsal, arqueada. Em uma análise filogenética incluindo todos os gêneros atualmente conhecidos de Neocoelidiinae (em preparação), as duas espécies de Acocoelidia formam um clado separado de Coelidiana, este último gênero mostrandose polifilético na análise.

Acocoelidia é aqui revalidado e este trabalho inclui a redescrição do gênero e de suas duas espécies. São fornecidas ilustrações e a distribuição geográfica conhecida das espécies estudadas.

\section{MATERIALEMÉTODOS}

O material estudado pertence às seguintes instituições: The United States National Museum of Natural History (USNM), Washington D.C., Estados Unidos e Ohio State University Collection (OSUC), Columbus, Estados Unidos.

A terminologia e a metodologia adotadas são as mesmas de Marques-Costa \& Cavichioli (2006). As ilustrações foram feitas com o auxílio de câmara clara acoplada ao microscópio estereoscópico ou, para estruturas de genitália menores, ao microscópio óptico.

Os tipos foram fotografados utilizando-se câmera digital diretamente acoplada em microscópio estereoscópico pertencente ao Laboratório de Sistemática e Bioecologia de Coleoptera da Universidade Federal do Paraná ou utilizandose um computador com software de automontagem, conectado a um microscópio estereoscópico com câmera digital acoplada.

Os dados complementares das etiquetas dos espécimes, adicionados pela primeira autora, estão entre colchetes.

\section{Acocoelidia DeLong, 1953, revalidado}

(Figs. 1-29)

Acocoelidia DeLong, 1953: 95, 130 (chave, descrição); Metcalf, 1964: 113 (catálogo).

Coelidiana Oman, 1936: 397, 409, 419 (descrição, ilustrações); Kramer, 1964: 274 (sinonímia).

Espécie-tipo: Acocoelidia unipuncta DeLong, 1953, por designação original. 
Diagnose. Coroa, pronoto e escutelo, sem manchas (Figs. 1-2, 12, 26, 28); carena transversal presente entre coroa e fronte; margem anterior da coroa, em vista dorsal, arqueada (Figs. 1$2,12,26,28$ ) e em vista lateral fortemente angulada (Figs. 4, 27, 29); ocelos na coroa, juntos à margem anterior (Figs. 1-2, 12); clípeo retangular, não intumescido, com margens laterais paralelas (Figs. 3, 13); margem posterior do pronoto emarginada em "V" (Figs. 1-2, 12); asas anteriores hialinas, com manchas marrons no clavo e próximo à base da segunda célula apical; com venação indistinta, exceto pela sutura claval, células apicais e ápices das três células anteapicais; com quatro células apicais e três células anteapicais; segunda célula apical estreitada e distal em relação a terceira e quarta células apicais (Figs. 5-6, 14); asas posteriores com $\mathrm{R}_{4+5}$ e $\mathrm{M}_{1+2}$ convergentes pré-apicalmente, fusionadas no ápice, formando uma única veia. Genitália do macho: pigóforo sem macrocerdas e processos, apenas com dente ventro-apical (Figs. 7, 15); placas subgenitais fusionadas apenas no terço basal (Figs. 8, 16); conetivo em forma de "Y" (Figs. 9, 18); edeago (Figs. 11, 19) e tubo anal sem processos (Figs. 7, 15).

Descrição. Coroa, pronoto e escutelo sem manchas contrastantes (Figs. 1-2, 12, 26, 28); coroa aproximadamente quadrangular, moderadamente projetada anteriormente e aproximadamente tão larga quanto longa; margem anterior em vista dorsal arqueada (Figs. 1-2, 12, 26, 28) e em vista lateral fortemente angulada (Figs. 4, 27, 29), com carena na transição entre coroa e fronte; margens laterais, adjacentes aos olhos, elevadas e não carenadas; superfície plana e lisa, sem estrias, com máculas coronais distintas; sutura coronal indistinta; ocelos na coroa, juntos à margem anterior e mais próximos aos olhos que à linha mediana (Figs. 1-2, 12); lobos supra-antenais, em vista lateral, oblíquos e carenados; alvéolos antenais pouco acima ou na altura da linha que tangencia os ângulos anteroventrais do olhos (Figs. 4, 27, 29); flagelos antenais mais longos que a metade basal das asas anteriores, quase tão longos quanto as asas; fronte com comprimento cerca de duas vezes sua largura basal, perfil convexo, sem intumescimento central na base ou carena; impressões musculares indistintas; suturas frontogenais não atingindo os ocelos (Figs. 3-4, 13); margens apicais das placas maxilares aproximadamente na mesma altura do ápice do clípeo, não o ultrapassando; loros em formato de meia-lua, margens inferiores não atingindo o ápice do clípeo; gena não cobrindo completamente os proepisternos, estes, em vista frontal, visíveis apenas pelos ápices; sutura epistomal distinta e completa, retilínea; clípeo retangular, com margens laterais paralelas (em A. unipuncta levemente alargado medianamente) e margem apical retilínea (Figs. 3, 13), em vista lateral, não intumescido (Fig. 4).

Tórax. Pronoto pouco mais largo que a cabeça, distância transumeral aproximadamente igual à distância transocular; comprimento mediano cerca de metade da distância transumeral; margem posterior levemente emarginada, com pequena reentrância mediana em forma de "V" (Figs. 1-2, 12); superfície lisa; carena dorsopleural completa e evidente; em vista ventral, mesotórax moderadamente intumescido; superfície do escutelo com textura lisa. Asa anterior cerca de três e meia a quatro vezes mais longa que sua largura máxima; sem pontuações, semi-hialina; venação indistinta, exceto pela sutura claval, células apicais e ápices das células anteapicais; quatro células apicais, todas aproximadamente retangulares, terceira e quarta células apicais alargadas apicalmente, segunda célula apical estreitada e distal em relação a terceira e quarta células apicais; três células anteapicais; apêndice estreito restrito à primeira célula apical (Figs. 5-6, 14). Asa posterior com três células apicais, $\mathrm{R}_{4+5}$ e $\mathrm{M}_{1+2}$ convergentes préapicalmente e fusionadas no ápice, formando uma única veia. Perna posterior: fórmula femoral $2+2+1$; tíbia: fileira anterodorsal com cerdas longas e grossas, com duas ou mais microcerdas intercalares; fileira posterodorsal com cerdas longas e grossas, pouco afastadas entre si, sem cerdas intercalares, uniformemente distribuídas por todo comprimento da tíbia; fileira anteroventral com cerdas moderadamente longas, afastadas entre si, sem bases proeminentes e sem cerdas intercalares, presentes somente na metade apical da tíbia; fileira posteroventral densamente cerdosa, com cerdas curtas na base, crescentes em comprimento em direção ao ápice; primeiro tarsômero tão longo quanto o comprimento combinado dos dois mais distais, superfície plantar com duas fileiras paralelas de microcerdas.

Genitália. Macho: pigóforo sem macrocerdas, aproximadamente retangular, alargado basalmente, estreitandose muito pouco em direção ao ápice, sem processos, apenas com dente ventro-apical (Figs. 7, 15). Valva inteiramente fusionada às placas subgenitais. Placas subgenitais aproximadamente triangulares e alargadas, fusionadas entre si apenas no terço basal; sem macrocerdas, com ápices arredondados, aproximadamente tão longas quanto o pigóforo e em vista lateral, sem dente apical (Figs. 8, 16). Estilos curtos, aproximadamente do mesmo comprimento do conetivo, com lobo pré-apical reduzido e arredondado, margens laterais lisas e cerdas no terço apical; em vista lateral, ápice levemente curvado ventralmente (Figs. 9-10, 17-18). Conetivo em forma de "Y", articulado à base do edeago, não bifurcado no ponto de articulação (Figs. 9, 18). Edeago alargado basalmente, estreitando-se gradativamente em direção ao ápice, sem processos; gonóporo apical (Figs. 11, 19). Tubo anal membranoso, sem processos (Figs. 7, 15).

Comprimento total. 5- 7,6 mm.

Distribuição geográfica. México, Guatemala, El Salvador, Costa Rica, Panamá e Venezuela.

Comentários. Acocoelidia pode ser separado dos demais gêneros, especialmente de Coelidiana, pelos seguintes caracteres: (1) margem anterior da coroa, em vista dorsal, arqueada (Figs. 1-2, 12, 26, 28); (2) asas anteriores com a segunda célula apical distal em relação à base da asa, se comparada à terceira célula apical (Figs. 5-6, 14); (3) asas anteriores com a segunda célula apical distal em relação à base da asa, se comparada à quarta célula apical (Figs. 5-6, 14). 

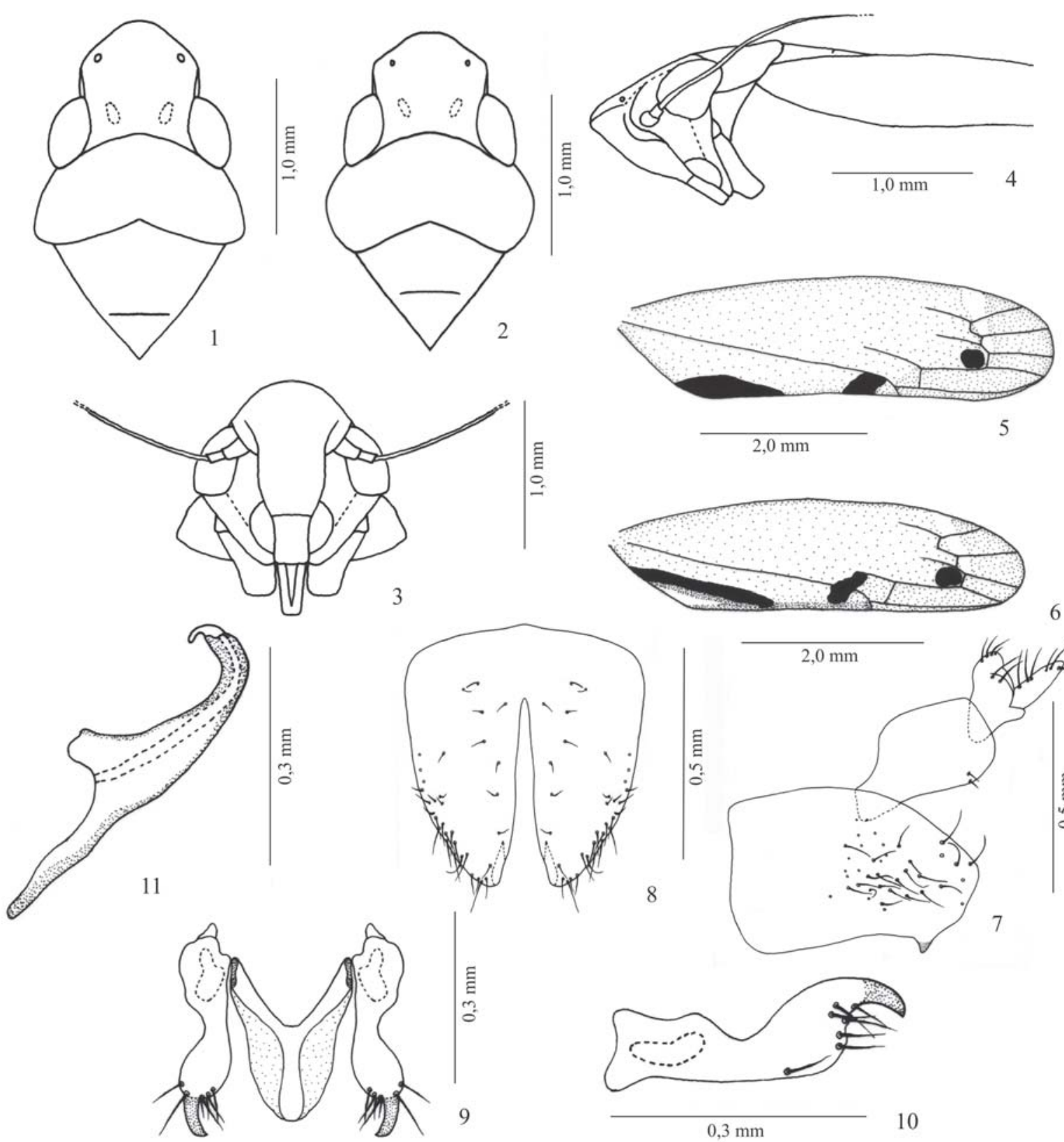

Figs. 1-11. Acocoelidia anomala DeLong, 1953: 1, 3-5, 7-11, holótipo macho; 2, 6, espécime macho, varições: 1-2, cabeça, pronoto e escutelo, vista dorsal; 3, cabeça, vista frontal; 4, cabeça, pronoto e escutelo, vista lateral; 5-6, asa anterior; 7, pigóforo e tubo anal, vista lateral; 8, valva e placas subgenitais, vista ventral; 9, estilos e conetivo, vista dorsal; 10, estilo, vista lateral; 11, edeago, vista lateral.

\section{Acocoelidia anomala DeLong, 1953}

(Figs 1-11,26-27)

Acocoelidia anomala DeLong, 1953: 111, 131 (descrição, ilustração); Metcalf, 1964: 113 (catálogo).

Coelidiana anomala; Kramer, 1967: 33 (chave); Chiamolera \& Cavichioli, 2005: 496 (chave).

Diagnose. Asas anteriores com três manchas marrons: uma escura na base do clavo, uma clara no ápice do clavo e uma outra clara anterior à base da segunda célula apical (Figs. 56); genitália do macho: conetivo com ramos basais e mediano estreitos e área membranosa ao redor do ramo mediano (Fig. 9); edeago, em vista lateral, com pequeno apódema dorsal truncado (Fig. 11).

Medidas (mm). Holótipo macho: comprimento total 5,96; comprimento mediano da coroa 0,64; distância transocular 1,20; distância interocular 0,68 ; comprimento mediano do pronoto 0,60; distância transumeral 1,40; largura máxima do escutelo 1,04; comprimento mediano do escutelo 1,0; comprimento das asas anteriores 4,65; largura máxima das asas anteriores 1,20.

Descrição. Caracteres estruturais como na descrição genérica, exceto genitália do macho: em vista lateral, pigóforo 

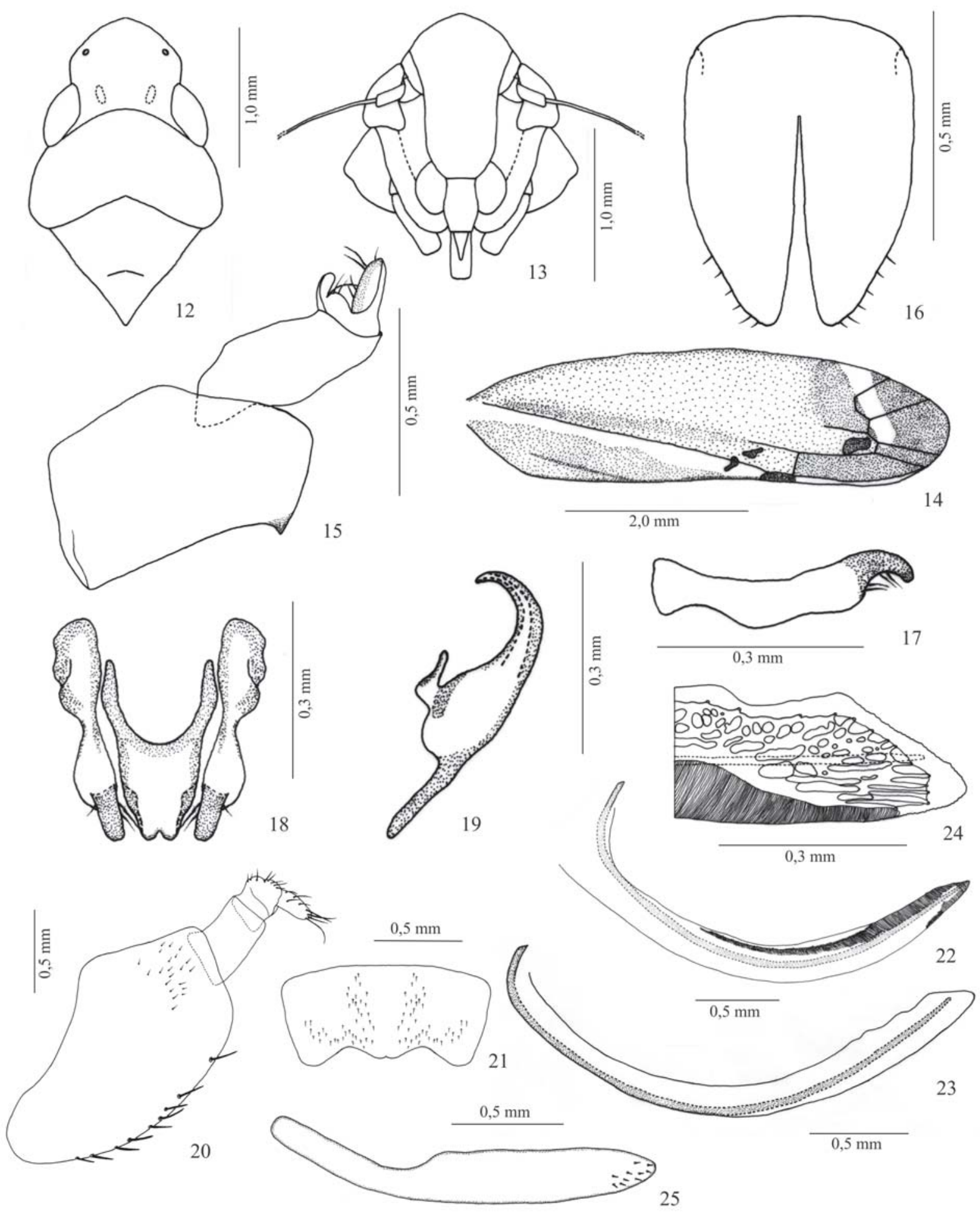

Figs. 12-25. Acocoelidia unipuncta DeLong, 1953: 12-19, holótipo macho; 20-25, parátipo fêmea: 12, cabeça, pronoto e escutelo, vista dorsal; 13, cabeça, vista frontal; 14, asa anterior; 15, pigóforo e tubo anal, vista lateral; 16, valva e placas subgenitais, vista ventral; 17, estilo, vista lateral; 18, estilos e conetivo, vista dorsal; 19, edeago, vista lateral; 20, pigóforo da fêmea, vista lateral; 21, esternito VII, vista ventral; 22, valva I, vista lateral; 23, valva II, vista lateral; 24, detalhe ápice da valva II; 25, valva III, vista lateral.

aproximadamente retangular, alargado basalmente, pouco estreitado no terço apical, sem processos e macrocerdas, com cerdas finas e longas na metade apical; margem posterior truncada e dente ventral esclerotinizado no ápice (Fig. 7).
Placas subgenitais levemente estreitadas no terço apical, com ápices arredondados e com microcerdas em toda sua extensão, mais alongadas nas margens externas do terço apical; cada placa cerca de duas vezes e meia mais longa que sua largura 

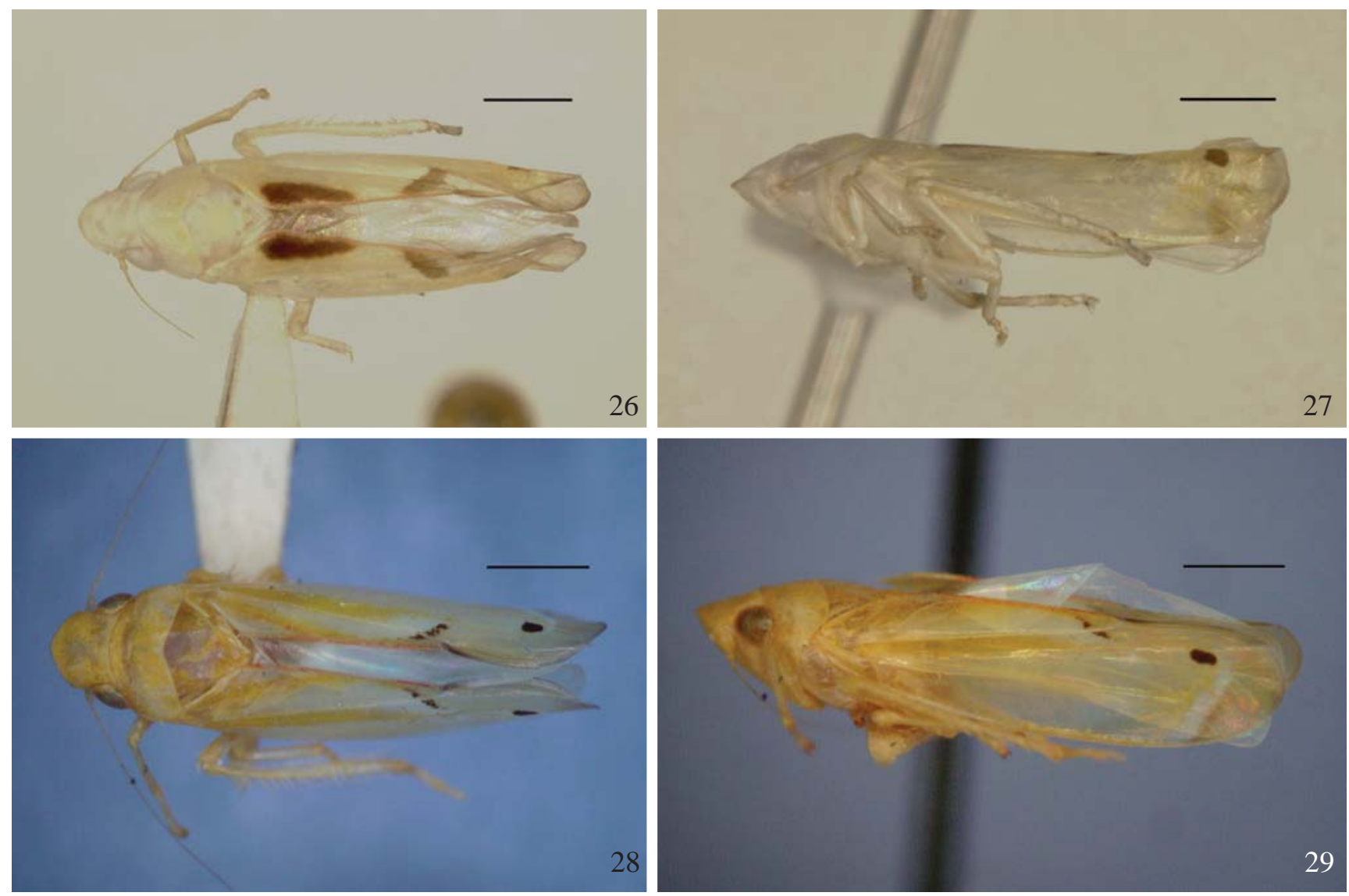

Figs. 26-29. Holótipos machos, vista dorsal e lateral: 26-27, Acocoelidia anomala DeLong, 1953; 28-29, Acocoelidia unipuncta DeLong, 1953. Escalas $=1,0 \mathrm{~mm}$.

basal (Fig. 8). Estilos curtos, com constrição mediana, e ápice levemente curvado ventralmente (Figs. 9, 10). Conetivo em forma de $\mathrm{Y}$, com ramos basais e mediano estreitos e área membranosa ao redor do ramo mediano (Fig. 9). Edeago, em vista lateral, sem processos, alargado e membranoso basalmente; base com pré-átrio estreito e longo, e pequeno apódema dorsal truncado; haste estreitando-se em direção ao ápice, metade apical curvada dorsalmente e anteriormente; margem ventral lisa, sem dentes (Fig. 11). Tubo anal curto e sem processos (Fig. 7).

Fêmea. Desconhecida.

Coloração geral. Amarelo-pálida a esbranquiçada. Cabeça, em vista frontal, inteiramente esbranquiçada, sem manchas distintas. Coroa, pronoto e escutelo amarelo-pálidos a esbranquiçados, sem manchas. Asas anteriores esbranquiçadas a amareladas nos dois terços basais e castanhas no terço apical, hialinas e com veias amareladas; com três manchas marrons: uma escura na base do clavo, uma clara no ápice do clavo e uma outra clara anterior à base da segunda célula apical; área hialina transversal pré-apical estendendo-se da base da terceira célula apical até a margem costal. Asas posteriores hialinas, sem coloração distinta, com veias esbranquiçadas a amareladas. Pernas amarelo-pálidas a esbranquiçadas, sem manchas e com cerdas da mesma cor.
Distribuição geográfica. Guatemala (Escuintla), El Salvador (La Paz), Costa Rica (localidade desconhecida) e Panamá (localidade desconhecida).

Material examinado. Holótipo macho (USNM): Costa Rica, Ho. 12304, 12.x.[19]48, 16837, [em] folha de Theobroma/ Acocoelidia anomala DeL[ong]/ Holótipo Acocoelidia anomala; Guatemala, Escuintla, viii.1959, N. L. H. Krauss [leg.]/ Coelidiana anomala (DeL.), Kramer, 1963 [det.], 1 macho (USNM); [El Salvador, La Paz], Santa María Ostuma, xi.1959, N. L. H. Krauss [leg.], 1 macho (USNM).

Variações. Máculas coronais indistintas; em alguns espécimes, cabeça pouco menos projetada anteriormente que no holótipo; coloração geral amarelo-escura e não amarelopálida a esbranquiçada como no holótipo; asa anterior com a margem anal e base do clavo alaranjados a avermelhados, a mancha marrom da base do clavo alongada, em forma de faixa diagonal, estendendo-se por toda metade basal do clavo; mancha marrom do ápice do clavo estendendo-se até o ápice da célula braquial; sutura claval e porção pré-apical manchadas de amarelo-escuro no espécime da Guatemala.

Condição do holótipo. Lateral direita do tórax colada em triângulo. Flagelos antenais quebrados a partir do terço médio. Perna anterior direita com tarso quebrado; perna posterior direita com os terços médio e apical da tíbia quebrados e tarso 
faltando; perna posterior esquerda com apenas o terceiro tarsômero quebrado. Asas anteriores e posteriores inteiras, não quebradas, apenas dobradas apicalmente. Abdome dissecado.

\section{Acocoelidia unipuncta DeLong, 1953}

(Figs. 12-25, 28-29)

Acocoelidia unipuncta DeLong, 1953: 97, 111, 130-131 (descrição, ilustrações); Metcalf, 1964: 114 (catálogo).

Acocoelidia unipunctata [sic] DeLong, 1953: 131 (nota comparativa). Coelidiana unipuncta; Kramer, 1964: 286 (ilustrações); 1967: 33 (chave); Chiamolera \& Cavichioli, 2005: 495 (chave).

Diagnose. Asas anteriores com quatro manchas marromescuras: uma na base do apêndice, uma pequena no ápice do clavo, uma pequena no ápice da célula braquial e uma aproximadamente arredondada, maior que as demais, no ápice da célula anteapical interna, anterior à base da segunda célula apical (Fig. 14); genitália do macho: conetivo com ramos basais estreitos e ramo mediano alargado (Fig. 18); edeago, em vista lateral, com pequeno apódema dorsal em forma de pé (Fig. 19).

Medidas (mm). Holótipo macho/parátipo fêmea: comprimento total $6,40 / 7,57$; comprimento mediano da coroa 0,70/0,92; distância transocular 1,25/1,48; distância interocular $0,75 / 0,84$; comprimento mediano do pronoto $0,65 / 0,72$; distância transumeral 1,55/1,72; largura máxima do escutelo 1,0/1,12; comprimento mediano do escutelo 1,0/1,20; comprimento das asas anteriores 5,20/5,75; largura máxima das asas anteriores $1,30 / 1,52$.

Descrição. Caracteres estruturais como na descrição genérica, exceto genitália do macho: em vista lateral, pigóforo aproximadamente retangular, alargado basalmente, pouco estreitado no terço apical, sem processos e macrocerdas; margem posterior truncada e dente ventral esclerotinizado no ápice (Fig. 15). Placas subgenitais levemente estreitadas no terço apical, com ápices arredondados e microcerdas no terço apical; cada placa cerca de duas vezes e meia mais longa que sua largura basal (Fig. 16). Estilos curtos, com constrição mediana, e ápice levemente curvado ventralmente (Figs. 1718). Conetivo em forma de $\mathrm{Y}$, ramos basais estreitos e ramo mediano alargado (Fig. 18). Edeago, em vista lateral, sem processos, alargado e membranoso basalmente; base com préátrio estreito e longo, e pequeno apódema dorsal em forma de pé; metade apical da haste estreitada e esclerotinizada, curvada dorsalmente e anteriormente; margem ventral lisa, sem dentes (Fig. 19). Tubo anal curto e sem processos (Fig. 15).

Fêmea. Externamente como o macho, exceto pelos caracteres de genitália: pigóforo com cerca de nove cerdas na margem posteroventral (Fig. 20). Esternito VII aproximadamente retangular, com ângulos póstero-laterais arredondados e projetados posteriormente, e margem posterior emarginada, medianamente arredondada e com pequena reentrância (Fig. 21). Valva I curvada dorsalmente, com ápice levemente estreitado e agudo, com esculturações nos terços médio e apical, atingindo as margens dorsal e ventral no terço apical (Fig. 22). Valva II mais longa que o pigóforo, curvada dorsalmente, fusionadas entre si nos terços basal e médio, separadas somente no terço apical; valvas direita e esquerda com ápice estreitado e arredondado; terço apical: margem dorsal com cerca de três a quatro dentes arredondados grandes e sem dentículos; ductos e poros não evidentes; margem ventral sem dentículos (Figs. 23-24). Valva III com ápice arredondado e cerdas destacadas no ápice (Fig. 25).

Coloração geral. Amarela. Cabeça, em vista frontal, sem manchas distintas. Coroa, pronoto e escutelo, inteiramente amarelos, com pequenas variações no tom de amarelo, sem manchas distintas. Asa anterior hialina, amarelada em sua maior parte, exceto apicalmente; área hialina transversal pré-apical estendendo-se da base da terceira célula apical até a margem costal; células apicais castanho-claras e margem anal do clavo alaranjada com uma pequena mancha laranja-escura na base; duas manchas amarelo-escuras: uma cobrindo quase que inteiramente o clavo e uma ao longo da sutura claval; quatro manchas marrom-escuras: uma na base do apêndice, uma pequena no ápice do clavo, uma pequena no ápice da célula braquial e uma mais ou menos arredondada, maior que as demais, no ápice da célula anteapical interna, anterior à base da segunda célula apical; venação amarela. Asa posterior esbranquiçada e hialina com veias amareladas. Pernas amarelas com cerdas da mesma cor.

Distribuição geográfica. México (Guerrero, San Luis Potosí), Guatemala (Jalapa), Costa Rica (San José), Panamá (Colón, Herrera) e Venezuela (Barinas).

Material examinado. Holótipo macho (OSUC), etiquetado: [México], Guerrero, Iguala, 11.ix.[19]39/ DeLong \& Plummer [leg.]/ D.M. DeLong Collection/ OSUC \# 0158113/ Holotype Acocoelidia unipuncta; Guatemala, [Jalapa], Finca los Cerritos, 06.vii.[19]44, E. J. Hambleton [leg.], 1 parátipo fêmea (USNM); ibidem, 09.ii.[19]36, light pocket banana hold, Phila $\mathrm{Pa} ., \mathrm{n}^{\circ} 28956,1$ parátipo fêmea (USNM); ibidem, 29.vii.[19]35, $\mathrm{n}^{\circ}$ 27555, 1 parátipo fêmea (USNM); Costa Rica, San José, Paso Ancho [y] San Sebastián, 06.ix.1936, C. H. Ballou [leg.], em Ficus carica L., no 4937, 2 parátipos fêmeas (USNM); Panamá, [Herrera], Porto Chitré, 24.x.[19]52, F. S. Blanton [leg.], Coelidiana unipuncta (DeL.) Kramer, 1963 [det.], 1 macho (USNM); [Colón], Mindi Dairy, 03.xii.1951, 1 macho (USNM); Venezuela, Barin[as], Barinitas, 22-26.ii.[19]69, Duckworth \& Dietz [leg.], 1 macho (USNM).

Variações. Asa anterior inteiramente amarelada, com tonalidade amarela-escura na porção pré-apical, anteriormente às bases das células apicais, não sendo mais escura no clavo e/ou sutura claval. Base do clavo com mancha marrom-escura arredondada e pequena, e não alaranjada como no holótipo; manchas marrom-escuras do ápice do clavo e célula braquial fusionadas entre si; uma segunda área hialina presente na asa anterior, próxima à margem costal pré-apical; as manchas marrons apresentam-se muito reduzidas em alguns parátipos fêmeas, algumas apresentando apenas duas manchas, a do ápice do clavo ou base do apêndice e a do ápice da célula anteapical interna. Uma das fêmeas da Guatemala apresentou coloração geral estramínea.

Condição do holótipo. Tórax ventralmente colado em triângulo entomológico. Abdome dissecado.

Agradecimentos. Ao Dr. Thomas Henry pela orientação durante o estágio de Doutorado Sanduíche realizado no USNM; aos Drs. Luciana 
Musetti e Creighton Freeman do OSUC, pelo empréstimo do holótipo de A. unipuncta; às Dras. Lúcia Massutti de Almeida e Cibele Stramare Ribeiro-Costa pelo uso do equipamento fotográfico; à Coordenação de Aperfeiçoamento de Pessoal de Nível Superior (CAPES) pela bolsa de Doutorado Sanduíche concedida à primeira autora em 2006; ao Conselho Nacional de Desenvolvimento Científico e Tecnológico (CNPq) pela bolsa de Pós-doutorado Especial em Taxonomia concedida à primeira autora em 2008 e pela bolsa de produtividade concedida ao segundo autor.

\section{REFERÊNCIAS}

Chiamolera, L. B. \& R. R. Cavichioli. 2005. Notas sobre Coelidiana Oman (Hemiptera, Cicadellidae, Neocoelidiinae) com descrição de três novas espécies do Brasil. Revista Brasileira de Zoologia 22: 494-500.
Delong, D. M. 1953. A synopsis of the tribe Neocoelidinii in the Americas (Homoptera-Cicadellidae). Lloydia 16: 93-131.

Kramer, J. P. 1964. A generic revision of the leafhopper subfamily Neocoelidiinae (Homoptera: Cicadellidae). Proceedings of the United States National Museum 115: 259-287.

Kramer, J. P. 1967. New neotropical Neocoelidiinae with keys to the species of Coelidiana, Xenocoelidiana, and Nelidina (Homoptera:Cicadellidae). Proceedings of the Entomological Society of Washington 69: 31-46.

Marques-Costa, A. P. \& R. R. Cavichioli. 2006. Revisão taxonômica, análise cladística e descrição de espécies novas de Aglaenita Spinola (Hemiptera, Cicadellidae, Neocoelidiinae). Revista Brasileira de Entomologia 50: $355-378$.

Metcalf, Z. P. 1964. General Catalogue of the Homoptera. Fascicle VI. Cicadelloidea. Part 11. Coelidiidae. United States Department of Agriculture, Agriculture Research Service, 182 p.

Oman, P. W. 1936. A generic revision of American Bythoscopinae and South American Jassinae. The University of Kansas Science Bulletin 24: $343-420$. 